\title{
Answer to the Letter to the Editor of S. Sabour concerning "Reliability and reproducibility analysis of the AOSpine thoracolumbar spine injury classification system by Chinese spinal surgeons" by J. Cheng et al. (Eur Spine J; 2016: DOI 10.1007/s00586-016-4842-4)
}

\author{
Peng Liu ${ }^{1}$
}

Received: 28 November 2016/Accepted: 28 November 2016/Published online: 8 December 2016

(C) Springer-Verlag Berlin Heidelberg 2016

\section{Dear Editor,}

I greatly appreciate the thoughtful comments from the author. In our paper, we used "The Kappa coefficient" to define the statistical test we applied, just as Urrutia [1] and Vaccaro [2]. Actually, we took the problem of proper statistical test into consideration when we dealt with experimental data, just as the respected author mentioned. The Kappa coefficient, proposed by Cohen in 1960, generally includes: simple Kappa coefficient, weighted Kappa coefficient, and total Kappa coefficient, and so on. Of these, the weighted Kappa coefficient has two types: Cicchetti-Allison and Fleiss-Cohen, which is usually used for ranked data. And we used the weighted Cohen Kappa coefficient in our study. Therefore, we do not think there is any inappropriate use of statistical test in our study.

Concerning the concept statistically significant has nothing to do with clinical importance of the findings, we agree with that.

Compared to Vaccaro's [1], Urrutia's [2] and Sadiqi's [3], however, participants in our study are much younger and have less clinical experience. And the agreement of our study is worse than those above mentioned. Moreover, there is a difference between two groups in our study. Then, we deduced that the level of the clinical experience had an effect on the classification. We also mentioned that single study population was one of the limitations in our paper, and that our study was a preliminary retrospective

Peng Liu

cheng_jie2016@163.com

1 Department of Orthopaedics, China-Japan Union Hospital, Jilin University, Changchun 130033, Jilin, China study based on radiology. To minimize the limitations associated with our study, prospective randomized control trials in different spine centers are necessary.

Therefore, our expression in the paper might lead to these misunderstandings mentioned by the author rather than our misinterpretation of data. Moreover, further RCT study about the effectiveness of the new AO classification for young physicians is necessary.

Compliance with ethical standards

Conflict of interest None.

\section{References}

1. Urrutia J, Zamora T, Yurac R, Campos M, Palma J, Mobarec S, Prada C (2015) An independent interobserver reliability and intraobserver reproducibility evaluation of the new AOSpine thoracolumbar spine injury classification system. Spine (Phila Pa 1976) 40(1):E54-E58

2. Vaccaro AR, Oner C, Kepler CK, Dvorak M, Schnake K, Bellabarba C, Reinhold M, Aarabi B, Kandziora F, Chapman J, Shanmuganathan R, Fehlings M, Vialle L (2013) AOSpine thoracolumbar spine injury classification system: fracture description, neurological status, and key modifiers. Spine (Phila Pa 1976) 38(23):2028-2037

3. Sadiqi S, Oner FC, Dvorak MF, Aarabi B, Schroeder GD, Vaccaro AR (2015) The influence of spine surgeons' experience on the classification and intraobserver reliability of the novel AOSpine thoracolumbar spine injury classification system - an international study. Spine (Phila Pa 1976) 40(23):E1250-E1256 